\title{
Consensus about image quality assessment criteria of breast implants mammography using Delphi method with radiographers and radiologists
}

Cláudia Sá dos Reis ${ }^{1,2,3^{*}}$, Isabelle Gremion ${ }^{1}$ and Nicole Richli Meystre ${ }^{1}$

\begin{abstract}
Aims: To identify image quality criteria that can be applied to assess breast implant (BI) mammograms according to radiologists and radiographers' perspectives and to explore the level of agreement about criteria priority.

Methods: A two-round Delphi method using a questionnaire was applied to identify the level of agreement between experts, asking them to rank each image criteria available for mammography according to 4 possible answers ( $1=$ need to have, $2=$ nice to have, $3=$ not pertinent/appropriate, $4=$ do not know). Criteria for craniocaudal (CC), mediolateral-oblique (MLO) and lateral (ML), with and without Eklund manoeuvre, were included. This process was repeated after removing the less relevant criteria.

Results: Between first and second rounds, different results were obtained regarding the criteria to assess CC and MLO images. Details for anatomic areas were considered the most relevant by radiographers during the first round, while general criteria were prioritised during the second round. Radiologists focused more on analysis of the spread of the breast tissue, if the breast was aligned with detector's centre and level of contrast. The analysis of implant flow, the BI anterior edge and the maximum retropulsion of $\mathrm{BI}$ when Eklund manoeuvre is performed were the specific aspects of Bl imaging considered as relevant for assessment.

Conclusions: The importance of each criterion used to assess BI mammograms was not the same between radiographers and radiologists, suggesting the two groups of experts are looking for different requirements from the image. Further education and training is necessary to align strategies for assessing BI mammograms, and some criteria need to be adapted to reduce subjectivity.
\end{abstract}

Keywords: Mammography practice, Technique, Eklund, Breast positioning, Protheses

\footnotetext{
* Correspondence: claudia.sadosreis@hesav.ch

${ }^{1}$ School of Health Sciences (HESAV), University of Applied Sciences and Arts

Western Switzerland (HES-SO), Av. de Beaumont 21, 1011 Lausanne,

Switzerland

2Discipline of Medical Radiation Sciences, School of Molecular and Life

Sciences, Curtin University, GPO Box U1987, Perth, Western Australia 6845,

Australia

${ }^{3}$ CISP - Centro de Investigação em Saúde Pública, Escola Nacional de Saúde

Pública, Universidade NOVA de Lisboa, Lisbon, Portugal
}

\section{Springer Open}

(c) The Author(s). 2020 Open Access This article is licensed under a Creative Commons Attribution 4.0 International License, which permits use, sharing, adaptation, distribution and reproduction in any medium or format, as long as you give appropriate credit to the original author(s) and the source, provide a link to the Creative Commons licence, and indicate if changes were made. The images or other third party material in this article are included in the article's Creative Commons licence, unless indicated otherwise in a credit line to the material. If material is not included in the article's Creative Commons licence and your intended use is not permitted by statutory regulation or exceeds the permitted use, you will need to obtain permission directly from the copyright holder. To view a copy of this licence, visit http://creativecommons.org/licenses/by/4.0/. 


\section{Key points.}

- Two groups of experts (radiographers/radiologist) are looking for different IQ criteria.

- Eklund manoeuvre mammograms should have specific IQ criteria.

- BI mammograms must consider maximum retropulsion of the implant.

- Visualisation of the implant anterior edge means all breast tissue is included.

- Necessary to adapt the PNL criterion to different BI locations (subglandular/subpectoral).

\section{Introduction}

Breast cancer screening programs (BCSP) are implemented across the world with the aim of reducing mortality by detecting cancer in its initial stage to increase chances of survival with earlier therapy [1]. Even being controversial [2], mammography is still considered the gold standard in some countries as the initial examination if equivocal clinical assessments or suspected implant complications are observed, particularly for women over 50 years old and those over 40 years with breast implants (BI) [3]. However, concerns about BI mammography have been raised due to the possible impairment of cancer detection [4-8]. Implants are denser compared to breast tissue [9] bringing challenges in image acquisition, reading and interpretation. The available guidelines for standard mammography do not present appropriate recommendations when a patient has $\mathrm{BI}$, regarding protocols and techniques or how to evaluate image quality (IQ), namely which criteria should be considered to ensure that the exam is adequate to perform diagnosis on images with implants that are denser compared to breast tissue [10-13]. With the implementation of digital mammography and breast tomosynthesis in BCSP across Europe, it is important to establish what are the best approaches for imaging the breast, including those with implants, namely protocols and techniques, but also how to evaluate and interpret the images. Considering there is limited evidence in published literature about IQ criteria for BI mammography assessment [7, 9, 14-33], this study aimed to identify image quality criteria that can be applied to assess breast implant mammograms according to both radiologists' and radiographers' perspectives. It also aimed to explore the level of agreement regarding the priority of each criterion to distinguish between those that must be verified and those that are not a priority to determine when an examination needs to be rejected and/or repeated.

\section{Methods}

To identify image quality criteria that can be applied to assess breast implant mammograms, a list of criteria available for standard mammography previously identified [34] was presented to a group of experts or stakeholders using a questionnaire and applying a two-round Delphi method [35-38]. The Delphi method provides an opportunity for experts/stakeholders to exchange viewpoints about a complex problem, to see how their evaluation of the issue aligns with others and to change their opinions, if desired, after reconsideration of the findings of the group's work. The main stakeholders involved in this specific context are typically radiographers and radiologists. Radiographers have their role in the assessment of IQ immediately after acquiring the images and radiologists subsequently evaluate the images, to interpret and report the examination. Because of their respective roles, they were brought together and, with the guidance of a facilitator, their informed opinions were interrogated to create a final list of criteria to be used for assessing BI mammography examinations. The facilitator explained the objectives of this study and also the scale used to classify each criteria. The aim of the listed criteria was to help with deciding if an examination, including images in craniocaudal $(\mathrm{CC})$, mediolateral-oblique (MLO), mediolateral (ML), acquired with and without Eklund Manoeuvre, presents all relevant imaging information to provide a diagnosis or if the examination should be repeated $[39,40]$. The priority of each criterion was additionally explored. A consensus approach was used to define the level of agreement between the group members $[35,41]$. According to the literature [35-37, 42], the group size can vary according to the purpose of the research or can be defined according to those who express interest in participating [36]. In this study, 10 participants (6 radiographers and 4 radiologists), all working in Swiss BCSP institutions, were invited to join the study after expressing their interest in the experience. All participants had a minimum of 7 years of experience in their respective profession.

The classical Delphi method was followed and involved 5 steps [36]:

1. A questionnaire was submitted online to the experts (participants), which presented a list of criteria that was based on a previous study [34]. They were asked to identify which items could be applicable to assess BI mammograms and add others that were not noted in the list (Tables 1 and 2);

2. The experts examined the criteria to categorise them as important or not and to ranked them according to the perceived level of importance as (a) need to have, (b) nice to have, (c) not pertinent/ appropriate and (d) I do not know;

3. Findings were analysed and presented to provide feedback to both radiographers and radiologists; 
Table 1 Criteria to assess mammography examinations grouped by type (positioning, artefacts, sharpness, parameters) in craniocaudal, mediolateral oblique and mediolateral mammograms

\begin{tabular}{|c|c|c|c|c|c|c|}
\hline Criteria & References & Type & 1 & 2 & 3 & 4 \\
\hline Breast centrally placed & {$[13,43-45]$} & Positioning (13) & & & & \\
\hline Presence of pectoral muscle (PM) & {$[11,13,45]$} & & & & & \\
\hline Pectoral muscle visualised down to the level of PNL & {$[11,13,45,46]$} & & & & & \\
\hline Visualisation of retroglandular adipose tissue & {$[11,13,45]$} & & & & & \\
\hline Medial border of the breast included on the image & {$[11,13,45,46]$} & & & & & \\
\hline Axillary tail demonstrated & {$[11,13,45,46]$} & & & & & \\
\hline Superior breast edge included & {$[13]$} & & & & & \\
\hline Inferior breast edge included & {$[45]$} & & & & & \\
\hline Full visualisation of inferior breast tissue & {$[45]$} & & & & & \\
\hline Inframammary angle clearly demonstrated & {$[11,13,45,46]$} & & & & & \\
\hline Nipple in profile or transected by skin & {$[11,13,45,46]$} & & & & & \\
\hline Nipple in the midline $\left(+/-10^{\circ}\right)$ & {$[11,45]$} & & & & & \\
\hline Symmetrical mirror images $R / L$ images & {$[11,13,45,46]$} & & & & & \\
\hline No skin folds & {$[13,45,46]$} & Artefacts (3) & & & & \\
\hline No artefacts & {$[45,46]$} & & & & & \\
\hline Skin edges visualised & {$[13]$} & & & & & \\
\hline Spread of breast tissue to differentiate adipose from fibroglandular tissue & {$[43,44]$} & Sharpness/compression (4) & & & & \\
\hline Sharpness of glandular tissue & {$[13,45,46]$} & & & & & \\
\hline Sharpness of vascular structures & {$[13,44]$} & & & & & \\
\hline Visually sharp reproduction of skin structure (rosettes from pores) & {$[13]$} & & & & & \\
\hline Good penetration of thicker areas without over penetration of thin areas & {$[45,46]$} & Parameters (2) & & & & \\
\hline Appropriate contrast & [44-46] & & & & & \\
\hline
\end{tabular}

1, need to have; 2 , nice to have; 3 , not pertinent/appropriate; 4 , I do not know

4. After subsequent readjustments, a second list of criteria was submitted for another round of assessment by the experts;

5. Finally, an agreement based on both rankings was attempted, to set a list of criteria to be applied by professionals working in a regional BCSP.

Parallel to the Delphi rounds, the same criteria identified during the literature review were used on a set of 1207 images to verify if they were applicable or not to real clinical scenarios and see if it is possible to assess each criterion when BI mammograms are acquired [34].

The 4-point Likert-type scale was used to rank each image criteria; the agreement percentage was calculated for the four levels of all criteria. The Kendall's $W$ (also known as Kendall's coefficient of concordance) was then used to identify the level of agreement amongst the raters. Kendall's $W$ ranges from 0 (no agreement) to 1 (complete agreement) [47]. The statistical analysis was performed using Statistical Package for the Social Sciences (SPSS) version 23 and Excel software. Subgroup analysis by profession was also performed.

Approval was obtained from participant stakeholders. All participants gave their written informed consent.

\section{Results}

The first round response rate was 100\% $(n=10)$ and for the second round was $90 \%(n=9)$. The number of criteria ranked during the first round were in total 25, distributed between positioning, parameters, sharpness/

Table 2 Criteria designed to assess the implant imaging in craniocaudal, mediolateral oblique and mediolateral mammograms

\begin{tabular}{|c|c|c|c|c|c|}
\hline Criteria & Type & 1 & 2 & 3 & 4 \\
\hline Maximum "retropulsion" of breast implant & Implant assessment (4) & & & & \\
\hline \multicolumn{6}{|c|}{ If Eklund is applied_-visibility of implant edge in the image } \\
\hline \multicolumn{6}{|l|}{ Maximum implant visualisation } \\
\hline Absence of artefacts (implant) & & & & & \\
\hline
\end{tabular}


compression and artefacts, and were adapted to each projection. Additionally, 4 criteria to assess the implant itself in a mammographic examination were considered (Table 2).

A. Criteria to assess image quality of $\mathrm{CC}$ projections performed with Eklund manoeuvre performed in women with BI

Criteria classified as "need to have" were sharpness of glandular tissue, absence of artefacts with a degree of consensus of $80 \%$; spread of breast tissue to differentiate adipose from fibroglandular tissue with a degree of consensus of $70 \%$; nipple in profile, maximum retropulsion of breast implant, breast aligned to the detector, absence of skin folders and adequate contrast between anatomical structures with a degree of consensus of $60 \%$. The visualisation of the medial border, retroglandular adipose tissue and axillary tail were considered as "nice to have" structures with a degree of consensus of $60 \%$. The sharp reproduction of skin structure (rosettes from pores) was considered as not necessary (Table 3 ).
The CC images acquired without Eklund technique had an extra criterion: the absence of flow in the implant area and symmetrical (in mirror) CC images.

Between the first and second Delphi rounds, it was possible to exclude some criteria (Table 4) due to poor scoring attributed to them, namely visualisation of pores, visualisation of the pectoral muscle and vascular anatomy. Contrast and adequate radiation penetration of the breast tissues were suggested as relevant in the first round outcomes and so were introduced into the second round and ranked high amongst the criteria.

B. Criteria to assess image quality of standard MLO projections performed in women with $\mathrm{BI}$

The most important criteria for MLO images were as follows: absence of artefacts with a degree of consensus of $78 \%$; sharpness and spread of breast tissues, inframammary angle clearly demonstrated, full visualisation of inferior breast tissue and maximum visualisation of pectoral muscle, nipple on profile, breast aligned with the detector centre, with a degree of consensus of $67 \%$.

Table 3 Criteria scoring for craniocaudal projection applying Eklund manoeuvre combining the opinions of both groups (radiologists and radiographers) and respective percentage (\%)

\begin{tabular}{|c|c|c|c|c|c|c|c|c|}
\hline \multirow[b]{2}{*}{ Criteria } & \multicolumn{4}{|c|}{ 1st round $n(\%)$} & \multicolumn{4}{|c|}{ 2nd round $n(\%)$} \\
\hline & $\begin{array}{l}\text { Need to } \\
\text { have }\end{array}$ & $\begin{array}{l}\text { Nice to } \\
\text { have }\end{array}$ & $\begin{array}{l}\text { Not } \\
\text { appropriated }\end{array}$ & $\begin{array}{l}\text { Do not } \\
\text { know }\end{array}$ & $\begin{array}{l}\text { Need to } \\
\text { have }\end{array}$ & $\begin{array}{l}\text { Nice to } \\
\text { have }\end{array}$ & $\begin{array}{l}\text { Not } \\
\text { appropriated }\end{array}$ & $\begin{array}{l}\text { Do not } \\
\text { know }\end{array}$ \\
\hline Breast centrally placed & $6(60)$ & $4(40)$ & & & $5(56)$ & $4(44)$ & & \\
\hline $\begin{array}{l}\text { 1st round: Presence of pectoral muscle } \\
\text { 2nd round: Visualisation of retroglandular } \\
\text { adipose tissue }\end{array}$ & $3(30)$ & $6(60)$ & $1(10)$ & & $5(56)$ & $4(44)$ & & \\
\hline Medial border of the breast included on the image & $5(50)$ & $4(40)$ & $1(10)$ & & $6(67)$ & $3(33)$ & & \\
\hline Axillary tail demonstrated & $3(30)$ & $3(30)$ & $4(40)$ & & $2(22)$ & $2(22)$ & $5(56)$ & \\
\hline Nipple in the midline $\left(+/-10^{\circ}\right)$ & $2(20))$ & $7(70)$ & $1(10)$ & & & & & \\
\hline Nipple in profile or transected by skin & $6(60)$ & $4(40)$ & & & $3(33)$ & $6(67)$ & & \\
\hline No skin folds & $5(50)$ & $4(40)$ & $1(10)$ & & $4(44)$ & $5(56)$ & & \\
\hline Skin edges visualised & $2(20)$ & $4(40)$ & $1(10)$ & $3(30)$ & & & & \\
\hline $\begin{array}{l}\text { Spread of breast tissue to differentiate adipose } \\
\text { for fibroglandular tissue }\end{array}$ & $7(70)$ & $3(30)$ & & & $4(44)$ & $5(56)$ & & \\
\hline Sharpness of vascular structures & $2(20)$ & $3(30)$ & $3(60)$ & $2(40)$ & & & & \\
\hline Sharpness of glandular tissue & $8(80)$ & $2(20)$ & & & $7(78)$ & $2(22)$ & & \\
\hline $\begin{array}{l}\text { Visually sharp reproduction of skin structures } \\
\text { (rosettes from pores) }\end{array}$ & & $4(40)$ & $5(50)$ & $1(20)$ & & & & \\
\hline No artefacts & $8(80)$ & $2(20)$ & & & $5(56)$ & $3(33)$ & $1(11)$ & \\
\hline Symmetrical mirror images & $2(20)$ & $7(70)$ & $1(10)$ & & $1(11)$ & $7(78)$ & $1(11)$ & \\
\hline Appropriate contrast & & & & & $6(67)$ & $3(33)$ & & \\
\hline Correct exposure & & & & & $6(67)$ & $3(33)$ & & \\
\hline Visibility of implant edge in the image & $5(50)$ & $3(30)$ & $1(10)$ & $1(20)$ & $3(33)$ & $5(56)$ & & $1(11)$ \\
\hline Maximum "retropulsion" of the implant & $6(60)$ & $4(40)$ & & & $7(78)$ & $1(11)$ & $1(11)$ & \\
\hline
\end{tabular}


Table 4 Criteria raking (mean values based in Kendall's $W$ ) comparison between first and second Delphi rounds regarding craniocaudal images performed with Eklund manoeuvre combining the opinions of both groups (radiologists and radiographers)

\begin{tabular}{|c|c|c|c|}
\hline Criteria & 1st round (average) & Criteria & 2nd round (average) \\
\hline Sharpness of breast tissue & 5.5 & Sharpness of breast tissue & 5.4 \\
\hline Absence of artefacts & 5.6 & Maximum retropulsion of implant & 5.8 \\
\hline Spread of breast tissue & 6.2 & Visualisation of medial breast tissue & 6.1 \\
\hline Nipple in profile & 6.8 & Adequate image contrast & 6.1 \\
\hline Maximum retropulsion of implant & 6.9 & Adequate image penetration & 6.1 \\
\hline Breast aligned with the detector's centre & 7.1 & Visualisation of retroglandular adipose tissue & 6.8 \\
\hline Visualisation of medial breast tissue & 8.1 & Breast aligned with the detector's centre & 7.0 \\
\hline Absence of skin folders & 8.1 & Absence of artefacts & 7.2 \\
\hline Visualisation of implant's anterior edge & 8.6 & Absence of skin folders & 7.6 \\
\hline Visualisation of retroglandular adipose tissue & 9.0 & Spread of breast tissue & 7.7 \\
\hline Nipple angle $+/-10^{\circ}$ & 9.9 & Nipple in profile & 8.5 \\
\hline Images in mirror & 10.1 & Visualisation of implant's anterior edge & 9.1 \\
\hline Axillary tail visible & 10.5 & Images in mirror & 10.3 \\
\hline Skin line visible & 11.6 & Axillary tail visible & 11.3 \\
\hline Visualisation of vascular anatomy & 11.8 & Visualisation of pectoral muscle & Left out \\
\hline Visualisation of pectoral muscle & 13.5 & Nipple angle $+/-10^{\circ}$ & Left out \\
\hline Skin line visible & 14.0 & Visualisation of vascular anatomy & Left out \\
\hline Adequate image contrast & Not included & Visualisation of pores along the skin & Left out \\
\hline Adequate image penetration & Not included & Skin line visible & Left out \\
\hline
\end{tabular}

The sharp reproduction of skin structure (rosettes from pores) and skin line visualisation were considered as not necessary.

Between the first and second Delphi rounds, some criteria were excluded as observed above for $\mathrm{CC}$ images (Table 5). One of criterion that became less relevant in the second round for images with $\mathrm{BI}$ was the level of visualisation of the pectoral muscle, namely the pectoral to nipple line (PNL). That criterion was left out of the questionnaire for the second round.

C. Criteria to assess image quality of ML projections performed with Eklund manoeuvre performed in women with BI

For ML images, the absence of artefacts, spread and sharp visualisation of breast tissues and breast aligned with the detector were considered as the most important parameters to be included in the analysis of ML images with a degree of consensus of $80 \%$. The visualisation of superior and inferior breast tissues, the absence of skin folders and the maximum retropulsion of the implant to reduce the superimposition over breast tissue were other criteria highlighted as important with a degree of consensus of $60 \%$. Adequate contrast and penetration were parameters not considered during the first Delphi round, but from the second round, these parameters were ranked in fifth and sixth positions (Tables 6 and 7).

Radiographers and radiologists did not agree in their ranking of 11 criteria for image quality assessment for the most common projections (CC and MLO) performed in women with BI (Figs. 1 and 2). The criteria considered as most relevant by radiographers to assess CC images were definition/sharpness of breast tissues, nipple in profile and spread of breast tissue. Radiologists noted the alignment of the breast with the detector's centre as "need to have" as well as definition/sharpness of breast tissues. Radiographers considered it important in MLO views to visualise the inframammary angle and also the visibility of inferior tissues, while radiologists were looking for the absence of artefacts, nipple not superimposed over breast tissue, absence of skin folders and definition/sharpness of breast tissue.

Kendall's coefficient of concordance was performed to verify the level of agreement between the two professional groups, and the differences were visible. The level of agreement between participants ranged from -0.13 to 0.7 for craniocaudal image criteria and -0.06 to 0.7 for MLO image criteria. 
Table 5 Criteria rakings (mean values based on Kendall's $W$ ) comparison between first and second Delphi rounds regarding mediolateral oblique image manoeuvre combining the opinions of both groups (radiologists and radiographers)

\begin{tabular}{|c|c|c|c|}
\hline \multicolumn{4}{|c|}{ Standard mediolateral oblique projection of breast implants } \\
\hline Criteria & 1st round (average) & Criteria & 2nd round (average) \\
\hline Absence of artefacts & 5.81 & Adequate image contrast & 6.22 \\
\hline Visualisation of inferior breast tissue & 7.69 & Adequate image penetration & 6.22 \\
\hline Inframammary angle open and visible & 7.69 & Sharpness of breast tissue & 7.06 \\
\hline Level of visualisation of pectoral muscle (PNL) & 7.75 & Inframammary angle open and visible & 7.11 \\
\hline Spread of breast tissue & 7.75 & Axillary tail visible & 7.11 \\
\hline Nipple in profile & 7.88 & Visualisation of inferior breast tissue & 7.28 \\
\hline Sharpness of breast tissue & 8.19 & Visualisation of superior breast tissue & 7.33 \\
\hline No flow (implant) & 8.50 & Breast aligned with the detector's centre & 7.94 \\
\hline Breast aligned with the detector's centre & 8.69 & Absence of artefacts & 8.5 \\
\hline Axillary tail visible & 8.69 & Spread of breast tissue & 8.78 \\
\hline Absence of skin folders & 9.25 & Nipple in profile & 8.83 \\
\hline Visualisation at least half of the implant & 9.44 & Visualisation of retroglandular adipose tissue & 8.94 \\
\hline Visualisation of superior breast tissue & 9.56 & Absence of skin folders & 9.67 \\
\hline Images in mirror (symmetry) & 9.69 & Visualisation at least half of the implant & 10 \\
\hline Visualisation of retroglandular adipose tissue & 10.56 & Images in mirror (symmetry) & 12.11 \\
\hline Visualisation of vascular anatomy & 14.00 & Inferior level of pectoral muscle & 12.89 \\
\hline Skin line visible & 14.06 & Level of visualisation of pectoral muscle (PNL) & Left out \\
\hline Visualisation of pores along the skin & 15.81 & No flow (implant) & Left out \\
\hline Inferior level of pectoral muscle & Left out & Visualisation of pores along the skin & Left out \\
\hline Adequate image contrast & Left out & Visualisation of vascular anatomy & Left out \\
\hline Adequate image penetration & Left out & Skin line visible & Left out \\
\hline
\end{tabular}

\section{Discussion}

The objectives of this study were to identify image quality criteria that are currently in use to assess BI mammograms according to radiologists and radiographers' perspectives and to explore the level of agreement about criteria priority.

To achieve these objectives a search was performed to identify possible criteria adapted to this specific context; however, no guidance was found [34]. This gap can impact on radiographers and radiologists' activities considering that is important to know what should be demonstrated on the image to select the most suitable protocol and to achieve examination goals. Not having a level of image quality that allows for the analysis of all relevant anatomy of the breast with implants means the diagnosis of breast pathologies can be compromised [48].

This study showed that the two professional groups look at BI mammograms in different ways, having individual strategies to assess IQ as demonstrated by the results of the Kendall concordance test. The agreement between radiographers and radiologists ranged from weak $(-0.13)$ to good agreement (0.7). Major differences in agreement were related to the priority of criteria, with radiographers searching for specific anatomical details (nipple in profile, visualisation of medial, superior and inferior breast tissues), while radiologists were focused on overall assessment such as contrast, breast aligned with the detector, beam penetration, spread and sharpness of breast tissue and absence of artefacts. In a study promoted by the Canadian Association of Radiologists [49], the problems related to the presence of artefacts in the image were emphasised as they can promote an increase in false positive rates compromising the diagnosis. On the other hand, another study stressed positioning deficiencies as the main causes of inadequate image quality. The presence of skin folds, the pectoral muscle being concave or thin or having a sagging breast on the MLO, or a portion of breast cut off were frequently highlighted [50]. However, having a BI means the relevance and priority of some criteria can vary compared to standard mammograms. For example, the visualisation and shape of pectoral muscle will change if a subglandular implant is placed inside the breast because the implant will be overlapping with the muscle. A portion of breast being cut off can also happen in this situation, due to the limitations in manipulating the implant when it is encapsulated [51] or even to include inframammary angle in MLO projections [34]. 
Table 6 Criteria scoring for mediolateral projection using Eklund manoeuvre combining the opinions of both groups (radiologists and radiographers) and respective percentage (\%)

\begin{tabular}{|c|c|c|c|c|c|c|c|c|}
\hline \multirow[t]{2}{*}{ Criteria } & \multicolumn{4}{|c|}{ 1st round $n(\%)$} & \multicolumn{4}{|c|}{ 2nd round $n(\%)$} \\
\hline & $\begin{array}{l}\text { Need to } \\
\text { have }\end{array}$ & $\begin{array}{l}\text { Nice to } \\
\text { have }\end{array}$ & $\begin{array}{l}\text { Not } \\
\text { appropriated }\end{array}$ & $\begin{array}{l}\text { Do not } \\
\text { know }\end{array}$ & $\begin{array}{l}\text { Need to } \\
\text { have }\end{array}$ & $\begin{array}{l}\text { Nice to } \\
\text { have }\end{array}$ & $\begin{array}{l}\text { Not } \\
\text { appropriated }\end{array}$ & $\begin{array}{l}\text { Do not } \\
\text { know }\end{array}$ \\
\hline Breast centrally placed & $4(80)$ & $1(20)$ & & & $5(56)$ & $4(44)$ & & \\
\hline $\begin{array}{l}\text { 1st round: Pectoral muscle (PM) visible down } \\
\text { to the pectoral muscle } \\
\text { 2nd round: PM visible until the upper edge of } \\
\text { the implant }\end{array}$ & $3((60)$ & $2(40)$ & & & $2(22)$ & $3(33)$ & $2(22)$ & $2(22)$ \\
\hline Visualisation of retroglandular adipose tissue & $2(40)$ & $3(60)$ & & & $4(44)$ & $5(56)$ & & \\
\hline Superior breast edge included & $3(60)$ & $2(40)$ & & & $6(67)$ & $3(33)$ & & \\
\hline Full visualisation of inferior breast tissue & $3(60)$ & $2(40)$ & & & $6(67)$ & $3(33)$ & & \\
\hline Inframammary angle clearly demonstrated & $1(20)$ & $3(60)$ & $1(20)$ & & $6(67)$ & $3(33)$ & & \\
\hline Nipple in profile or transected by skin & $3(60)$ & $1(20)$ & & & $4(44)$ & $5(56)$ & & \\
\hline No skin folds & $3(60)$ & $2(40)$ & & & $3(33)$ & $6(67)$ & & \\
\hline Skin edges visualised & & & $3(60)$ & $2(40)$ & & & & \\
\hline $\begin{array}{l}\text { Spread of breast tissue to differentiate adipose } \\
\text { for fibroglandular tissue }\end{array}$ & $3(60)$ & $2(40)$ & & & $4(44)$ & $5(56)$ & & \\
\hline Sharpness of vascular structures & $1(20)$ & & $3(60)$ & $1(20)$ & & & & \\
\hline Sharpness of glandular tissue & $4(80)$ & $1(20)$ & & & $6(67)$ & $3(33)$ & & \\
\hline $\begin{array}{l}\text { Visually sharp reproduction of skin structures } \\
\text { (rosettes from pores) }\end{array}$ & & $2(40)$ & $3(60)$ & & & & & \\
\hline Visibility of implant edge in the image & $1(20)$ & $4(80)$ & & & & & & \\
\hline Maximum "retropulsion" of the implant & $3((60)$ & $2(22)$ & & & & & & \\
\hline No artefacts & $4(80)$ & $1(20)$ & & & $5(56)$ & $3(33)$ & $1(11)$ & \\
\hline Symmetrical mirror images & $3((60)$ & $2(40)$ & & & $1(11)$ & $7(78)$ & & $1(11)$ \\
\hline Appropriate contrast & & & & & $7(78)$ & $2(22)$ & & \\
\hline
\end{tabular}

This study also showed that the priority of each criterion is different amongst the two professional groups, it being desirable to take into account the likelihood of attaining each criterion in further studies. Radiographers prioritise the aesthetic side while radiologists look to see if the relevant information is noted in the image or not [52]. Previous studies showed that is effectively important as an overall assessment of image quality [43, 52], it being crucial to have all breast tissues included and correctly demonstrated. However, the proposed strategies to assess mammograms were still considered subjective for some criteria, and the need for standardisation was highlighted [53]. The words "appropriate" and "general amount" are being used but they are open to individual interpretation bringing variations in the final IQ analysis. Additionally, BI are an extra challenge because there is a superimposition of a dense structure over soft breast tissues, increasing the possibility of hiding relevant pathologies [43]. For that reason, modified positioning is required (Eklund) to help with the reduction of the amount of breast tissue superimposition. This is managed by displacing the implant posteriorly against the chest wall and pulling breast tissue over and in front of the implant, facilitating also the compression [51]. But these changes in positioning bring concomitant changes in the image appearance, making it necessary that radiographers know exactly what is required to be demonstrated, and communicating with radiologists to achieve a better alignment between both Education also has a role to play as revealed in a previous study about mammography education in Europe [54] which demonstrated that positioning and image quality assessment are very challenging, leading to students demanding more training and a wider exposure to different clinical scenarios. Specific training for BI imaging could be an approach that would reduce professional differences.

The main limitations of this study are related to a different number of participants in both rounds (first 10, second 9) and also the 2 groups of professionals were not the same size (6 radiographers and 4 radiologists), which may affect the subgroup analyses. ML view and Eklund manoeuvre were not currently performed by all participants and implant location (subglandular or subpectoral) was not considered, and that has an impact on the visible anatomy as demonstrated previously [34]. 
Table 7 Criteria rakings (mean values based on Kendall's $W$ ) comparison between first and second Delphi rounds regarding mediolateral image manoeuvre combining the opinions of both groups (radiologists and radiographers)

\begin{tabular}{|c|c|c|c|}
\hline \multicolumn{4}{|c|}{ Criteria for mediolateral projection of breast implants mammograms with Eklund manoeuvre } \\
\hline Criteria & 1st round (average) & Criteria & 2nd round (average) \\
\hline Sharpness of breast tissue & 5.2 & Sharpness of breast tissue & 6.0 \\
\hline Absence of artefacts & 5.4 & Visualisation of inferior breast tissue & 6.8 \\
\hline Breast aligned in the detector's centre & 5.5 & Maximum retropulsion of implant & 6.8 \\
\hline Visualisation of superior breast tissue & 6.4 & Superior edge $2 \mathrm{~cm}$ & 7.4 \\
\hline Visualisation of inferior breast tissue & 6.4 & Adequate image contrast & 7.4 \\
\hline Spread of breast tissue & 6.4 & Adequate image penetration & 7.4 \\
\hline Maximum retropulsion of implant & 6.6 & Visualisation of superior breast tissue & 8.3 \\
\hline Absence of skin folders & 6.9 & Breast aligned in the detector's centre & 8.3 \\
\hline Images in mirror & 6.9 & Nipple in profile & 8.4 \\
\hline Visualisation of retroglandular adipose tissue & 7.6 & Absence of artefacts & 9.0 \\
\hline Visualisation of implant's anterior edge & 9.3 & Absence of skin folders & 9.6 \\
\hline Inframammary angle open and visible & 10.0 & Spread of breast tissue & 9.9 \\
\hline Visualisation of pectoral muscle anterior edge & 12.4 & Inframammary angle open and visible & 10.0 \\
\hline Visualisation of vascular anatomy & 12.7 & Visualisation of retroglandular adipose tissue & 10.8 \\
\hline Visualisation of pores along the skin & 13.3 & Images in mirror & 12.1 \\
\hline Skin line visible & 15.0 & Visualisation of pectoral muscle anterior edge & 12.2 \\
\hline Nipple in profile & Left out & Visualisation of implant's anterior edge & 12.7 \\
\hline Superior edge $2 \mathrm{~cm}$ & Left out & Visualisation of vascular anatomy & Left out \\
\hline Adequate image contrast & Left out & Visualisation of pores along the skin & Left out \\
\hline Adequate image penetration & Left out & Skin line visible & Left out \\
\hline
\end{tabular}

This means that during the ranking process the decision of the participants would not consider the changes in image.

Further research is required for the identification of quality targets that should be reached in daily practice. However, the risk of omitting indicators was mitigated by the expertise of the panel who were given the opportunity to suggest additional ones, considering they were familiar with the relevant literature and BI imaging. That is also one of the advantages of using the Delphi method, where opinions can be different from one round to another [52], making the list richer.

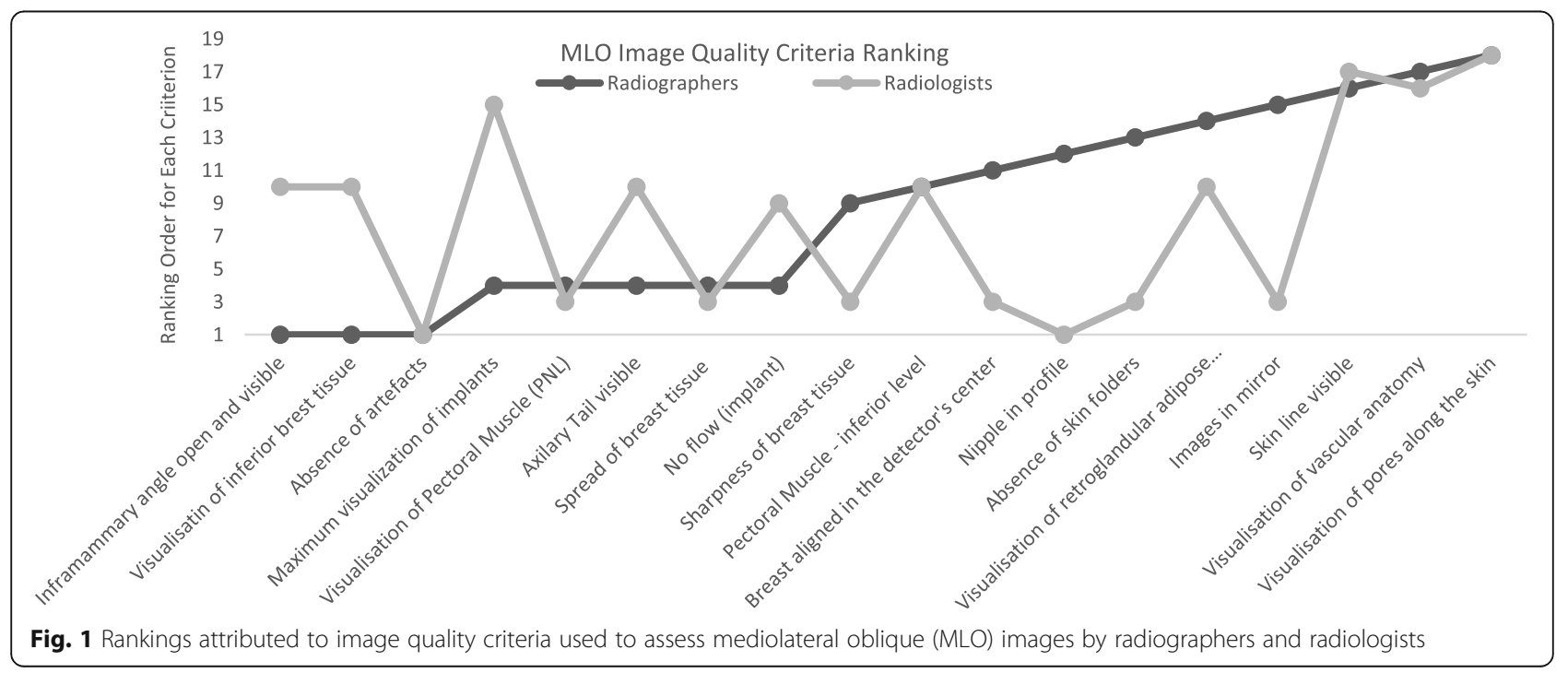




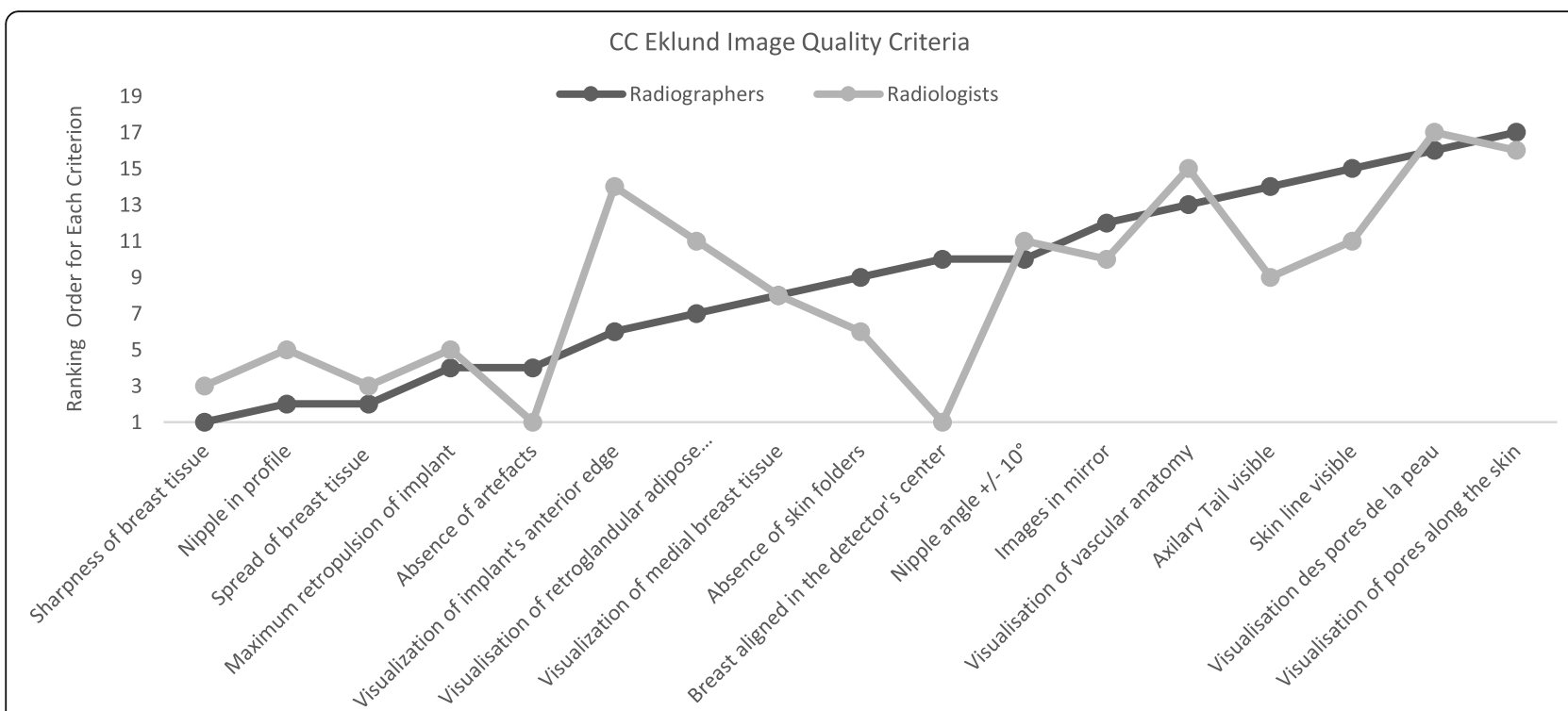

Fig. 2 Average rankings attributed to image quality criteria used to assess craniocaudal (CC) images performed with Eklund Manoeuvre by radiographers and radiologists

Even with published work showing that is possible to use the Delphi method to identify quality indicators and prioritise criteria to be included in guidelines, it was challenging to conduct this study. The lack of standardisation of definitions, number of participants, optimal variance of rating scale, the best means for each answer and image quality assessment methodologies can lead to an incomplete list of criteria to assess BI examinations.

Therefore, basic criteria to start the image analysis were identified for BI such as maximum retropulsion of implant, visualisation of anterior edge of implant and no artefacts (such as flow). But some criteria identified as necessary are still subjective and that can be considered a limitation of this study, for example, "adequate contrast" and "adequate beam penetration".

\section{Conclusions}

Radiologists and radiographers did not consider the same parameters as relevant to assess image quality of BI mammograms; however, a list of criteria to assess BI mammograms was produced focusing on aspects of positioning, exposure parameters, sharpness and compression regarding the implant itself. This difference in the approach to image assessment shows that it is necessary to develop a standardised strategy in BI mammography, including different criteria adapted to each type of implant (subglandular versus subpectoral) as the changes promoted in the anatomy are different. Considering the experts' opinions, the criteria to assess BI mammograms must consider maximum retropulsion of the implant, visualisation of the anterior edge of the implant and no artefacts (such as flow). The spread and sharpness of breast tissues are the other "need to have" parameters that do not differ from standard mammography. The revision of the PNL line and inclusion of the inframmamary angle criteria seem to be necessary to adapt to this specific context taking in consideration the implant location (subglandular/subpectoral).

Education and training to align radiographers and radiologists understandings is also necessary to have examination outcomes that match the interpretation requirements that lead to the optimal diagnostic outcomes of breast pathologies.

\section{Abbreviations}

BCSP: Breast cancer screening programs; BI: Breast implants;

CC: Craniocaudal; IQ: Image quality; ML: Mediolateral; MLO: Mediolateral oblique; PNL: Pectoral to nipple line; SPSS: Statistical Package for the Social Sciences

\section{Acknowledgements}

The authors would like to acknowledge the experts (radiographers and radiologists) who participated on Delphi data collection and contributed to the discussions about image quality criteria that should be added to evaluate breast implant mammograms.

\section{Authors' contributions}

All authors contributed to this work. CSR made contributions to the conception and design of the study and data analysis and substantively revised it. IG made contributions to the design and data collection and revised. NRM made substantial contributions to the conception and design of the study and analysis of the data and substantively revised it. All authors read and approved the final manuscript. All authors agree with the publication and they gave consent to publish this work.

\section{Funding}

Haute école Spécialisée de Suisse Occidentale (SAGE-X n66636)

\section{Availability of data and materials}

Data generated or analysed during this study are included in this published article. 


\section{Ethics approval and consent to participate}

Ethical approval and consents to participate were obtained from participant institutions and from the Ethical Board of Swiss Ethics Committees on Research.

\section{Competing interests}

The authors declare that they have no competing interests.

Received: 17 January 2020 Accepted: 5 March 2020

Published online: 03 April 2020

\section{References}

1. The National Cancer Institute (2011) International Cancer Screening Network. In: Organ. Breast Cancer Screen. Programs 27 ICSN Countries, 2007-2008. http://appliedresearch.cancer.gov/icsn/breast/screening.html

2. Keating NL, Pace LE (2018) Breast cancer screening in 2018: time for shared decision making. JAMA 319:1814 https://doi.org/10.1001/jama.2018.3388

3. American College of Radiology Breats Implants Evaluation. In: Appropriateness Criteria - Am. Coll. Radiol. https://acsearch.acr.org/list/ GetEvidence?Topicld=239\&TopicName=Breast Implant Evaluation. Accessed $24 \operatorname{Jan} 2019$

4. Smalley S (2003) Breast implants and breast cancer screening. J Midwifery Womens Health 48:329-337. https://doi.org/10.1016/S1526-9523(03)00280-0

5. Bantick GL, Taggart I (1995) Mammography and breast implants. Br J Plast Surg 48:49-52. https://doi.org/10.1016/0007-1226(95)90032-2

6. Daskalaki A, Bliznakova K, Pallikarakis N (2016) Evaluation of the effect of silicone breast inserts on X-ray mammography and breast tomosynthesis images: a Monte Carlo simulation study. Phys Med 32:353-361 https://doi. org/10.1016/.ejmp.2016.01.478

7. Raj SD, Karimova EJ, Fishman MDC et al (2017) Imaging of breast implantassociated complications and pathologic conditions: breast imaging. Radiographics 37:1603-1604 https://doi.org/10.1148/rg.2017170025

8. Juanpere S, Perez E, Huc O, Motos N, Pont J, Pedraza S (2011) Imaging of breast implants—a pictorial review. Insights Imaging 2:653-670 https://doi. org/10.1007/s13244-011-0122-3

9. Shah AT, Jankharia BB (2016) Imaging of common breast implants and implant-related complications: a pictorial essay. Indian J Radiol Imaging 26: 216-225 https://doi.org/10.4103/0971-3026.184409

10. del Turco MR (2010) Implementation of the European Union Guidelines for quality assurance in breast cancer screening and diagnosis. In: Europa DONNA (ed) European Journal of Cancer Supplements. Elsevier Ltd, pp 189-189

11. EUSOMA - GUIDELINES AND PUBLICATIONS - Breast Unit Guidelines - Index. http://www.eusoma.org/Engx/Guidelines/Guideline.aspx?cont=breast. Accessed 26 Jan 2015

12. Kanal KM, Krupinski E, Berns EA et al (2013) ACR-AAPM-SIIM practice guideline for determinants of image quality in digital mammography. J Digit Imaging 26:10-25 https://doi.org/10.1007/s10278-012-9521-3

13. European Commission (1996) European guidelines on quality criteria for diagnostic radiographic images. European Communities, Luxembourg

14. Spuur K, Webb J, Poulos A, Nielsen S, Robinson W (2018) Mammography image quality and evidence based practice: analysis of the demonstration of the inframammary angle in the digital setting. Eur J Radiol 100:76-84 https://doi.org/10.1016/j.ejrad.2018.01.004

15. Mclntosh SA, Horgan K (2008) Augmentation mammoplasty: effect on diagnosis of breast cancer. J Plast Reconstr Aesthet Surg 61:124-129 https:// doi.org/10.1016/j.bjps.2007.06.035

16. Berry MG, Davies DM (2010) Breast augmentation: part i - a review of the silicone prosthesis. J Plast Reconstr Aesthet Surg 63:1761-1768 https://doi. org/10.1016/j.bjps.2009.07.047

17. Stöblen F, Rezai M, Kümmel S (2010) Imaging in patients with breast implants - results of the First International Breast (Implant) Conference 2009. Insights Imaging 1:93-97 https://doi.org/10.1007/s13244-010-0021-z

18. Lowes $S$, MacNeill F, Martin L et al (2018) Breast imaging for aesthetic surgery: British Society of Breast Radiology (BSBR), Association of Breast Surgery Great Britain \& Ireland (ABS), British Association of Plastic Reconstructive and Aesthetic Surgeons (BAPRAS). J Plast Reconstr Aesthet Surg 71:1521-1531 https://doi.org/10.1016/j.bjps.2018.07.004

19. Moneme NC, Curtis J (2019) Radiographer mammographers' attitudes towards implementing new techniques for imaging the augmented breast, after viewing a training DVD or receiving cascade training: a survey. Radiography (Lond) 25:39-45 https://doi.org/10.1016/.jadi.2018.07.006

20. Parr O, Dunmall K (2018) An evaluation of online information available for women with breast implants aged 47-73 who have been invited to attend the NHS Breast Screening Programme. Radiography (Lond) 24:315-327 https://doi.org/10.1016/j.radi.2018.03.008

21. Eklund GW, Busby RC, Miller SH, Job JS (1988) Improved Augmented imaging breast of the augmented breast. AJR Am J Roentgenol 151:469473 https://doi.org/0361-803X/88/1513-0463

22. Uematsu $T$ (2008) Screening and diagnosis of breast cancer in augmented women. Breast Cancer 15:159-164 https://doi.org/10.1007/s12282-008-0036-1

23. Bassetti E, Pediconi F, Luciani ML, Santucci E, Miglio E, Candreva R (2011) Breast prosthesis: management of patients after plastic surgery. J Ultrasound 14:113-121 https://doi.org/10.1016/j.jus.2011.03.001

24. Murphy C (2005) An overview of radiological technology in the management of breast cancer. Can J Med Radiat Technol 36:6-14. https:// doi.org/10.1016/S0820-5930(09)60081-5

25. Beckett JR, Kotre CJ (2000) Estimation of mean glandular dose for mammography of augmented breasts. Phys Med Biol 45:3241-3252

26. Tuli R, Flynn RA, Brill KL, Sabol JL, Usuki KY, Rosenberg AL (2006) Diagnosis, treatment, and management of breast cancer in previously augmented women. Breast J 12:343-348 https://doi.org/10.1111/j.1075-122X.2006.00273.x

27. Silva FAR, Souza LF, Salmon CEG (2011) Breast phantom with silicomne implant for evaluation in conventional mammography. J Appl Clin Med Phys 12:199-206

28. Ganott MA, Harris KM, Ilkhanipour ZS, Costa-Greco MA (1992) Augmentation mammoplasty: normal and abnormal findings with mammography and US. Radiographics 12:281-295 https://doi.org/10.1148/radiographics.12.2.1561417

29. Stivala A, Rem K, Leuzzi S et al (2017) Efficacy of ultrasound, mammography and magnetic resonance imaging in detecting breast implant rupture: A retrospective study of 175 reconstructive and aesthetic sub-pectoral breast augmentation cases. J Plast Reconstr Aesthet Surg 70:1520-1526 https://doi. org/10.1016/j.bjps.2017.05.051

30. Kopans DB, Moore RH, Mccarthy KA et al (1997) Should women with implants or a history of treatment for breast cancer be excluded from mammography screening programs? AJR Am J Roentgenol 168:29-31 https://doi.org/0361-803X/97/1681-29

31. Kam K, Lee E, Pairawan $S$ et al (2015) The effect of breast implants on mammogram outcomes. Am Surg 81:1053-1056 https://doi.org/10.1002/ we.1770

32. Smathers RL, Boone JM, Lee L, Berns EA, Miller RA, Wright AM (2007) Radiation dose reduction for augmentation mammography. AJR Am J Roentgenol 188:1414-1421 https://doi.org/10.2214/AJR.06.0998

33. Silva FAR, Souza LF, Salmon CEG, Souza DN (2011) Breast phantom with silicone implant for evaluation in conventional mammography. J Appl Clin Med Phys 12:199-206 https://doi.org/10.1120/jacmp.v12i1.3340

34. Sá dos Reis C, Gremion I, Richli Meystre N (2020) Study of breast implants mammography examinations for identification of suitable image quality criteria. Insights Imaging 11:3 https://doi.org/10.1186/ s13244-019-0816-5

35. Vernon W (2009) The Delphi technique: a review. Int J Ther Rehabil 16:6976 https://doi.org/10.12968/ijtr.2009.16.2.38892

36. John-Matthews JS, Wallace MJ, Robinson L (2017) The Delphi technique in radiography education research. Radiography (Lond) 23:S53-S57 https://doi. org/10.1016/j.radi.2017.03.007

37. Mullen PM (2003) Delphi: myths and reality. J Health Organ Manag 17:37-52 https://doi.org/10.1108/14777260310469319

38. Keeney S, Hasson F, McKenna HP (2001) A critical review of the Delphi technique as a research methodology for nursing. Int J Nurs Stud 38:195200. https://doi.org/10.1016/S0020-7489(00)00044-4

39. Lelivelt H, Ongeval C van, Jacobs J, et al (2010) EUREF type testing - clinical evaluation protocol. Nijmegen

40. European Communities/EUREF (2006) European guidelines for quality assurance in breast cancer screening and diagnosis, 4th ed. European Communities, Luxembourg

41. Nworie J (2011) Using the Delphi technique in educational technology research. TechTrends 55:24-30 https://doi.org/10.1007/s11528-011-0524-6

42. Gargon E, Crew R, Burnside G, Williamson PR (2019) Higher number of items associated with significantly lower response rates in COS Delphi surveys. J Clin Epidemiol 108:110-120 https://doi.org/10.1016/j.jlinepi. 2018.12.010 
43. Li Y, Poulos A, Mclean D, Rickard M (2010) A review of methods of clinical image quality evaluation in mammography. Eur J Radiol 74:122-131 https:// doi.org/10.1016/j.jrad.2009.04.069

44. Reis C, Pascoal A, Sakellaris T, Koutalonis M (2013) Quality assurance and quality control in mammography: a review of available guidance worldwide. Insights Imaging 4:539-553 https://doi.org/10.1007/s13244-013-0269-1

45. Meystre NR, Bulliard J-L (2011) Test et validation d'une grille d'évaluation dédiée à la mammographie. Fonds National Suisse de la Recherche Scientifique

46. European Commission, European Communities/European Reference Organisation for Quality Assured Breast Screening and Diagnostic Services (2006) European guidelines for quality assurance in breast cancer screening and diagnosis., 4th ed. European Communities, Brussels

47. Gisev N, Bell JS, Chen TF (2013) Interrater agreement and interrater reliability: key concepts, approaches, and applications. Res Soc Adm Pharm 9:330-338 https://doi.org/10.1016/j.sapharm.2012.04.004

48. Dumky H, Leifland K, Fridell K (2018) The art of mammography with respect to positioning and compression-a Swedish perspective. J Radiol Nurs 37: 41-48 https://doi.org/10.1016/j.jradnu.2017.11.006

49. Guertin MH, Théberge I, Zomahoun HT, Dufresne MP, Pelletier É, Brisson J (2018) Mammography clinical image quality and the false positive rate in a Canadian breast cancer screening program. Can Assoc Radiol J 69:169-175 https://doi.org/10.1016/j.carj.2017.12.003

50. Guertin M-H, Théberge I, Dufresne M-P et al (2014) Clinical image quality in daily practice of breast cancer mammography screening. Can Assoc Radiol J 65:199-206 https://doi.org/10.1016/j.cari.2014.02.001

51. Eklund G, Busby R, Miller S, Job J (1988) Improved imaging of the augmented breast. AJR Am J Roentgenol 151:469-473 https://doi.org/10. 2214/ajr.151.3.469

52. Taylor K, Parashar D, Bouverat G et al (2017) Mammographic image quality in relation to positioning of the breast: a multicentre international evaluation of the assessment systems currently used, to provide an evidence base for establishing a standardised method of assessment. Radiography (Lond) 23:343-349 https://doi.org/10.1016/j.radi.2017.03.004

53. Hill C, Robinson L (2015) Mammography image assessment; validity and reliability of current scheme. Radiography (Lond) 21:304-307 https://doi.org/ 10.1016/.jadi.2015.07.005

54. Sá dos Reis C, Strøm B, Richli-Meystre N et al (2018) Characterization of breast imaging education and insights from students, radiographers and teaching staff about its strengths, difficulties and needs. Radiography (Lond) 25:e1-e10 https://doi.org/10.1016/j.radi.2018.07.001

\section{Publisher's Note}

Springer Nature remains neutral with regard to jurisdictional claims in published maps and institutional affiliations.

\section{Submit your manuscript to a SpringerOpen ${ }^{\circ}$ journal and benefit from:}

- Convenient online submission

- Rigorous peer review

- Open access: articles freely available online

- High visibility within the field

- Retaining the copyright to your article

Submit your next manuscript at $\boldsymbol{\nabla}$ springeropen.com 